\title{
KINEMATIC DISCREPANCY OF HYDROSTATIC DRIVE OF UNMANNED GROUND VEHICLE
}

\begin{abstract}
The study presents the issue of kinematic discrepancy of hydrostatic drive systems of high mobility vehicles, and its impact on the presence of the unfavourable phenomenon of circulating power. Furthermore, it presents a theoretical discussion concerning the capacity of the compensation of kinematic discrepancy by a hydrostatic drive system on the basis of tests using static characteristics.
\end{abstract}

\section{Introduction}

The tasks requested from the Unmanned Ground Vehicles (UGV) during rescue activities and military missions put forward high requirements in terms of their mobility and manoeuvrability. They include, among other things, the capacity of UGV to move on rough terrain $(20-30 \mathrm{~cm})$, hills with the inclination angle of $40 \%\left(22^{\circ}\right)$, low carrying capacity areas $=150 \mathrm{kPa}$, overcoming typical field obstacles, i.e.: debris, logs, ditches [1]. The above requirements are possible to be satisfied by applying a hydrostatic drive system (HDS) and a long-travel suspension [2].

The advantages of hydrostatic drive systems, such as the CVT, protection of the motor against overload, wide range of rotational speeds of hydraulic motors, make them commonly used in vehicles and machines meant for work in difficult off-road conditions [3], the example of which are working machines.

Driving with UGVs on very rough terrain or with different values of dynamic radiuses of road wheels, which may be caused by uneven load or different value of pressure in tires, results in wheels rotating with different rotary speeds

* Military University of Technology, ul. Gen. S. Kaliskiego 2, 00-906 Warsaw 49, Poland; E-mails: stanislaw.konopka@wat.edu.pl, marian.lopatka@wat.edu.pl, miroslaw.przybysz@, wat.edu.pl 
(Fig. 1). The phenomenon is known as the kinematic discrepancy and it is defined by a degree of kinematic discrepancy. The degree of kinematic discrepancy $\Delta$ of a system is the ratio of the difference between the numbers of wheels rotation $\omega^{\prime}, \omega^{\prime \prime}$ performed on a given road section (while rotating without slipping), and the number of rotations of the wheel rotating with greater speed [4]

$$
\Delta=\frac{\omega^{\prime}-\omega^{\prime \prime}}{\max \left(\omega^{\prime}, \omega^{\prime \prime}\right)}
$$

where:

$\omega^{\prime}, \omega^{\prime \prime}$ - angular velocity of vehicles wheels.

Kinematic discrepancy of the drive system may be examined between the wheels located on the same axis or between different axes. This study presents the issue of kinematic discrepancy between different axes.

a)

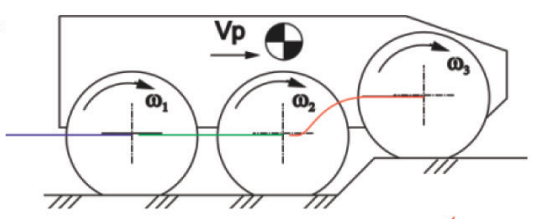

b)

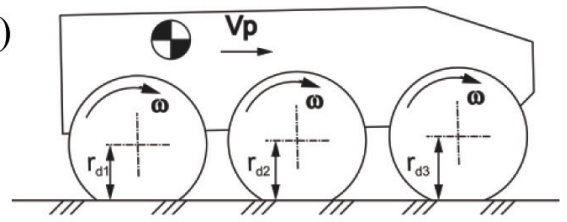

c)

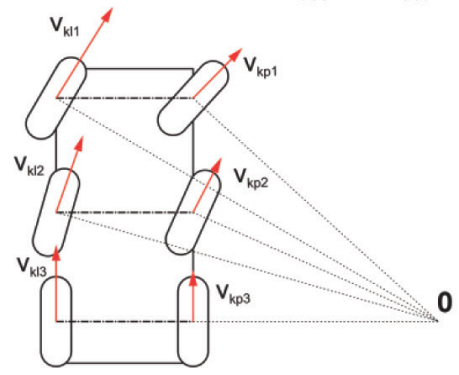

Fig. 1. Kinematic discrepancy in six-wheels vehicle: a) drive over obstructions terrain,

b) different radius of wheels, c) driving in curvilinear motion

The requirements for UGVs with regard to their mobility lead to increased requirements concerning the cooperation of the drive system with the road bed. It is important, because the lack of adjustment of rotational speed of wheels to the kind of road they rotate on leads to many slips at the places where the wheel touches the road bed (positive - in the case when the wheel rotates with a smaller speed than it would result from the movement kinematically consistent with the road bed, and negative slips - in the case of the wheel rotating with a greater speed than it would result from the movement kinematically consistent with the road bed) $[5,6]$. The wheel with a positive slippage is in this case the wheel inhibiting the vehicle, which causes the introduction of additional power stream coming from the road bed, called the circulating power, to the system. This phenomenon leads, among other things, to significant limitation of the capacity of 
overcoming field obstacles, and the reduction in total efficiency of the drive system as a result of the increase in pressures in the system, and in the cases of long-term operation, it leads to faster wearing or even damage of the system.

Hydrostatic drive systems are characterized by great kinematic rigidity, which is associated with small compressibility of the working agent, i.e. a medium in HDS that ensures power transfer from the pressure generator to the receivers, which are the hydraulic motors responsible for the road wheels drive. This feature results in the fact that HDS provides a great kinematic accuracy of performed movements, but it is also sensitive to the kinematic discrepancies that may appear. The accuracy depends mainly on internal leaks resulting from the construction features of the used elements and pressure drops on particular elements [6]. The leaks enable, to some extent, the differentiation of rotational speed of the wheels necessary for covering the kinematic discrepancy - which is defined as kinematic flexibility. On the other hand, the capacity for covering the kinematic discrepancy by means of ensuring kinematic flexibility of the system is called the kinematic discrepancy compensation.

Thus, it is necessary to examine the impact of leaks in the system on the capacity for differentiating the speed of the wheels, enabling the provision of appropriate cooperation between the wheel and the road bed when driving with large values of kinematic discrepancy, avoiding the development of the circulating power phenomenon.

This paper presents the issue of kinematic discrepancy resulting from driving on very rough terrain and its impact on a hydrostatic drive system, and it includes an estimation of the kinematic discrepancy compensation capacity in a hydrostatic drive system.

\section{Construction solution of hydrostatic driving systems used in increased mobility vehicles}

One way of eliminating the problem of the circulating power phenomenon in the system is applying a hydraulic differential mechanism by powering the hydraulic motors connected with each other in a parallel manner (Fig. 2). The sum of all absorbencies of the hydraulic motors is covered with the efficiency of the pump, which is expressed as the relation

where:

$$
Q_{p}=\sum_{i=1}^{n} Q_{s i}
$$

$Q_{p}$ - efficiency generated by hydraulic pump, $\Sigma Q_{s i}$ - sum of absorbing capacity of the hydraulic motors, $n$ - number of hydraulic motors. 
a)

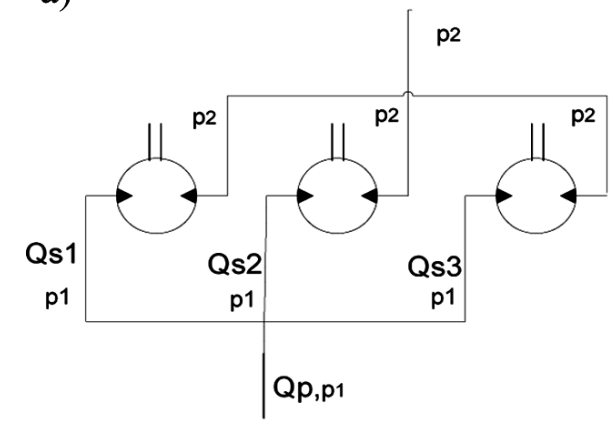

b)

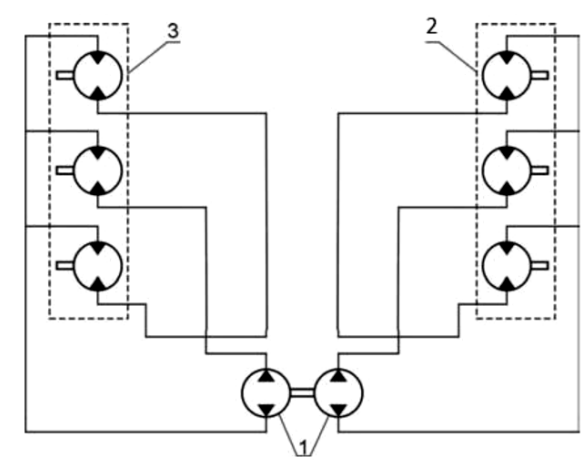

Fig. 2. Parallel system of supply of hydraulic motors: a) pressure drops in hydraulic system;

b) diagram of connecting hydraulic motors in parallel

However, such a solution has a serious disadvantage, namely, if one takes into account that pressures in supplying and runoff lines of the motors have the same value, resulting from their load, then as a result of reducing pressure decrease in any of the motors, limitation or even a loss of the capacity of generating the driving torque on other wheels shall occur. The effect may occur in the case of reducing the pressure of wheels on the road bed, driving on the road bed characterized by a low value of adhesion coefficient or in extreme cases by tearing the wheel off the bed (Fig. 3).

a)

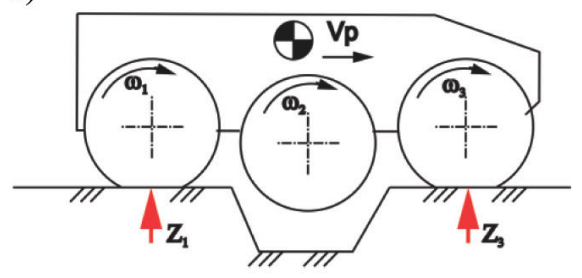

b)

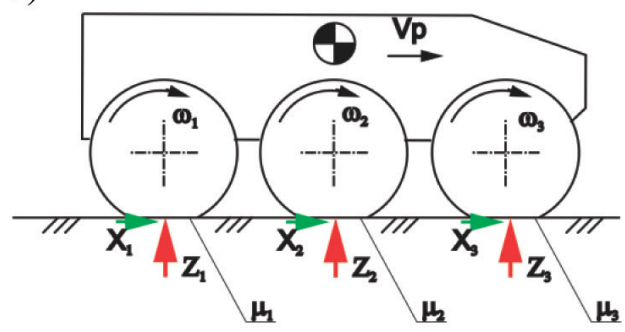

c)

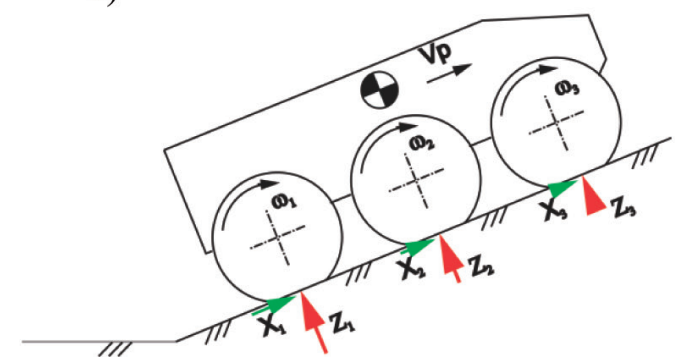

Fig. 3. Limitation or a loss of drive ability: a) overcoming a ditch; b) low value of coefficient adhesion; c) unequal load on road wheels 
The unfavourable effect described above can be eliminated by introducing a HDS kinematic rigidity of the wheels belonging to one board of the vehicle, understood as their drive with the same speed regardless of the load. This may be achieved by connecting the motors in a serial or parallel manner with the use of flow dividers responsible for dividing the working agent to the motors regardless of their load (Fig. 4). In the case of serial connection of the motors, total efficiency from the supplying pump is pumped subsequently by the motors of one side

$$
Q_{p}=Q_{s 1}=Q_{s 2}=Q_{s 3},
$$

where:

$Q_{p}$ - capacity of the pump,

$Q_{s i}-$ absorptivity of the hydraulic motor.

a)

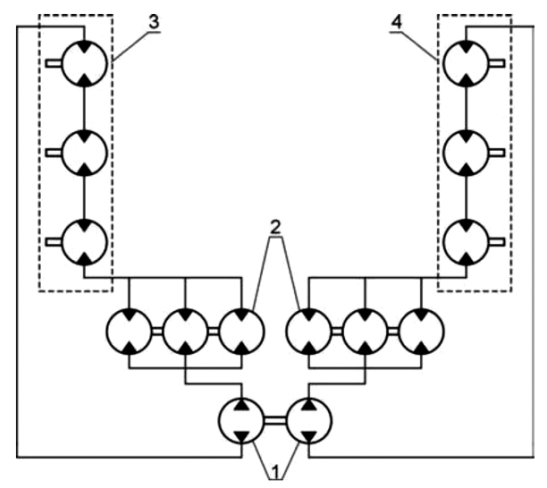

b)

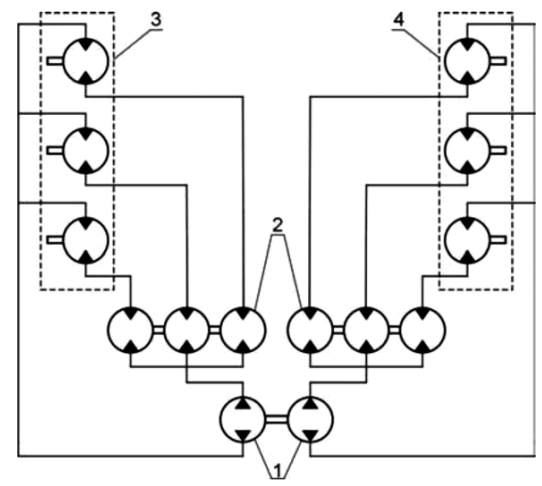

Fig. 4. Kinematically stiff driving system: a) connecting hydraulic motors in series; b) connecting motors in series with the use of gear flow dividers; 1 - positive displacement pumps; 2 - gear flow dividers; 3, 4-hydraulic motors [8]

As a result, the pressure increase generated by the supplying pump covers the sum of pressure drops at the hydraulic motors (Fig. 5a)

where:

$$
\Delta p_{p}=\Sigma \Delta p_{s i}
$$

$\Delta p_{p}$ - pressure generated by the positive displacement pump, $\Sigma \Delta p_{s i}-$ sum of pressure drops in hydraulic motors.

In the case of a parallel connection of the motors, each of them can use the maximum working pressure generated by the pump (Fig. 5b); total efficiency is divided proportionally to each of the hydraulic motors in accordance with relation (2). Using both configurations of connections in one drive system, one can obtain the ride and off-road gears. 
a)

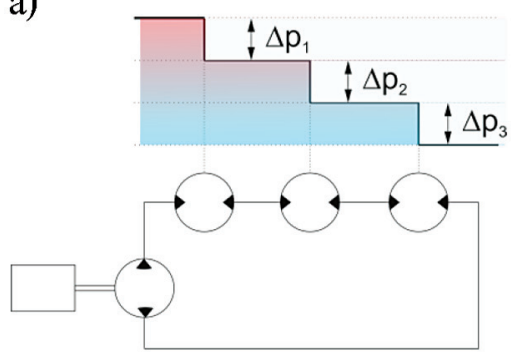

b)
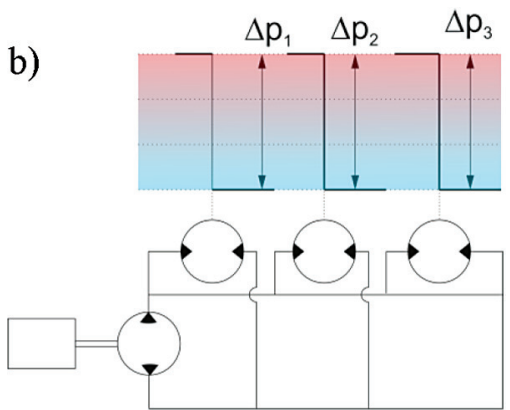

Fig. 5. Pressure drop in hydraulic motors [7]

The systems of this type are used first of all in off-road vehicles of high mobility and such a system has been used in the engineering support robot "Marek" (Fig. 6a). The proposed drive system is composed of two main piston pumps of variable efficiency, each of whom is responsible for power supply to the motors belonging to a separate side (1), the flow dividers of the working agent (2) and the hydraulic motors used for powering the road wheels (3) (Fig. 6b). The system is equipped with valves enabling the change of the motors connection in a serial and parallel manner. The system was adopted for tests of the kinematic discrepancy compensation capacity.

a)

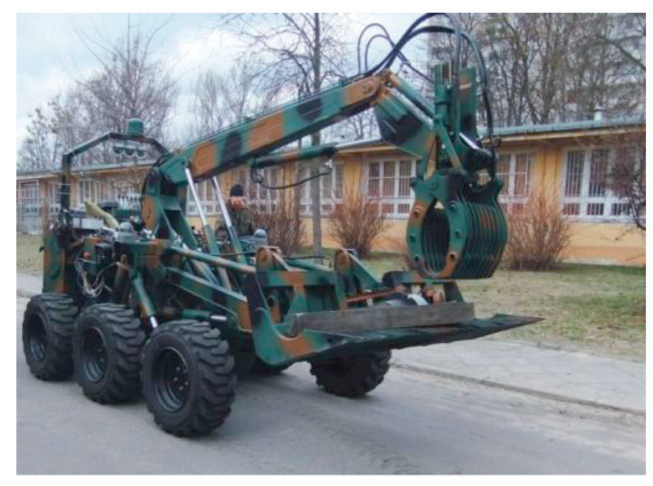

b)

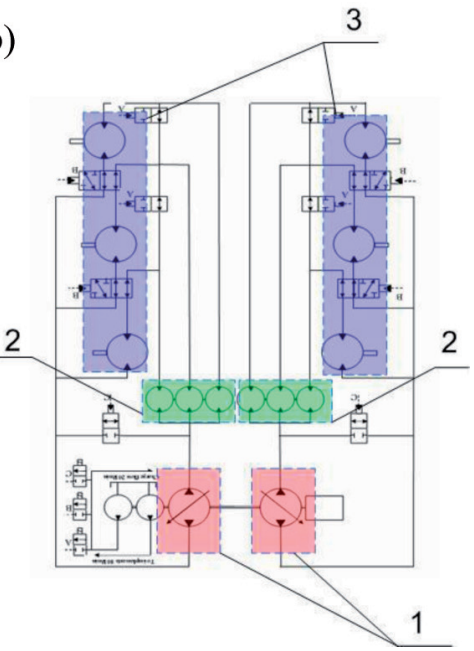

Fig. 6. Unmanned ground vehicle "Marek": a) vehicle; b) hydrostatic driving system: 1 - positive displacement pumps supplying the system; 2 - working medium gear flow dividers; 3 - hydraulic motors [9] 


\section{Kinematic discrepancy compensation in the hydraulic system}

In order to examine the capability for differentiation of rotational speed of the road wheels of the vehicle, it is necessary to determine volumetric losses in the drive system and their accumulated impact on rotational speeds of the shafts of hydraulic motors. The value of those leaks can be determined on the basis of characteristics and data made available by the manufacturers of hydraulic subassemblies. In the adopted system of the engineering support robot Marek (Fig. 6), the capacity of kinematic discrepancy compensation depends on the leaks on the flow divider and in hydrostatic motors. The leaks in the pump do not affect the capacity of kinematic discrepancy compensation.

For the analysis of the kinematic discrepancy compensation capacity, we adopted piston motors of comparable absorbency of ca. $400 \mathrm{~cm}^{3} / \mathrm{rev}$ and the capacity for generating the driving torque; the motors differed in structure:

1. the gerotor engine Danfos TMT 400,

2. the piston engine Rexroth MCR5 380.

Flow dividers with comparable values of nominal and working flows at comparable nominal pressures were adopted for the analysis; the flow dividers differed in accuracy of dividing the working agent:

1. the gear flow divider by ViVoil with a $2 \%$ accuracy of the working medium flow division at the nominal working conditions;

2. the gear flow divider by ViVoil with a 5\% accuracy of the working medium flow division at the nominal working conditions;

3. the throttling divider Rexroth RTM, with variable characteristics of the division depending on the speed of the working medium flow (Fig. 7).

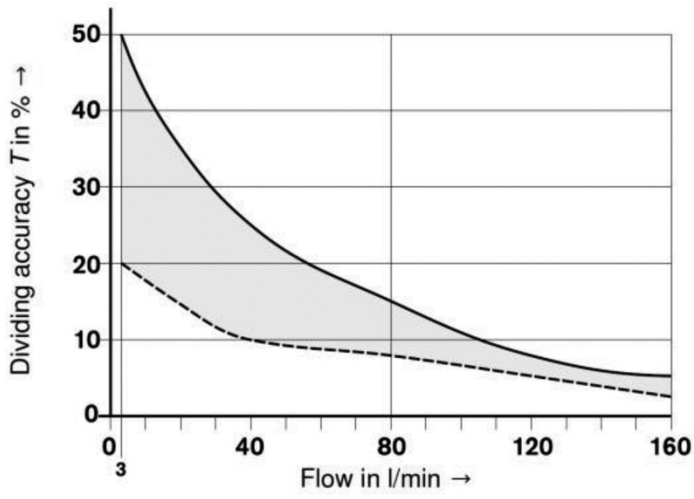

Fig. 7. Characteristics of the accuracy of dividing the throttling stream Rexroth RTM of the gear flow divider [10] 
The following conditions of the system operation were assumed for tests:

a. driving with small speed and large movement resistance requiring the development of large values of driving forces, which corresponds to the movement of the vehicle in a difficult terrain using the off-road gear;

b. driving with a great speed with small movement resistance, achieved with the race gear in a series system.

\subsection{Estimation of the capacity for kinematic discrepancy compensation in the off-road mode}

The analysis was conducted for the speed of the vehicle of $v_{j}=1 \mathrm{~m} / \mathrm{s}$, which, under the assumption of the dynamic radiuses of wheels $r_{d}=0.35 \mathrm{~m}$, requires the provision of absorbency to each of the three motors $Q_{s}=12 \mathrm{dm}^{3} / \mathrm{min}$, which means that the pump supplying the side of the vehicle should generate the efficiency of $Q_{p}=36 \mathrm{dm}^{3} / \mathrm{min}$. It was assumed that the maximum pressure drop on hydraulic motors and the pressure generated by the pump are limited by a safety valve to the value of $\Delta p_{p}=30 \mathrm{MPa}$ and $\Delta p_{s i}=30 \mathrm{MPa}$ accordingly. In the anticipated speed range, the volumetric efficiency of the gerotor motor Danfos TMT 400 is, for the assumed maximum pressure $\eta_{v}=0.82$, while for to the piston motor Rexroth MCR5 380 under the same conditions $\eta_{v}=0.86$ (Fig. 8).

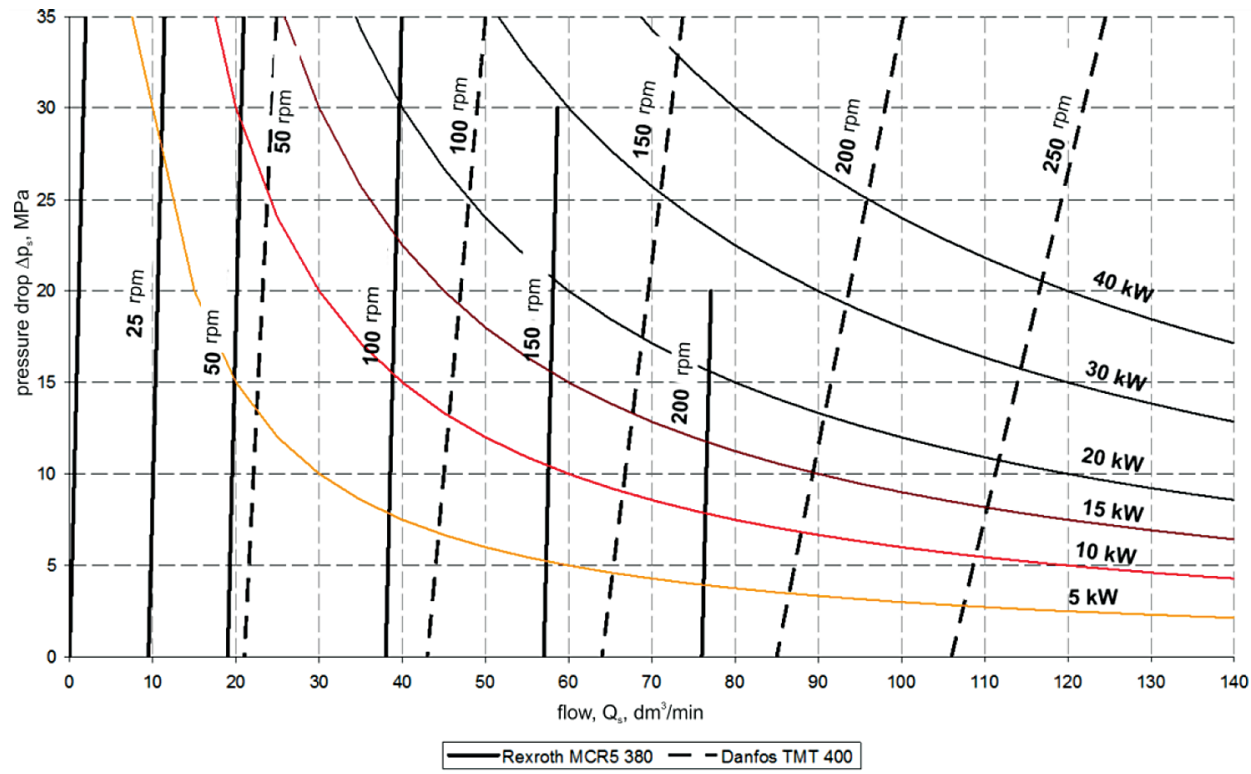

Fig. 8. Comparison of the volumetric hydraulic motors characteristics by means of a curve of the constant speed - worked out on the basis of the data provided by the producers $[11,12]$ 
The starting point for determining the kinematic discrepancy compensation capacity is the balance of pressure drops generated on the flow divider (Fig. 9), which is the kinematic coupling of the hydraulic system lines. Since the sections of the divider are connected to one another mechanically, the sum of pressure drops on particular sections must be equal to zero, which is expressed by the formula

$$
\sum_{i=1}^{n} \Delta p_{d z i}=0
$$

where:

$\Delta p_{d z i}$ - pressure drops at the sections of the flow divider.

Thus, the average value of pressures in the lines at the inlet and outlet from the divider must be equal, according to the relation

$$
\frac{1}{n} \sum_{i=1}^{n} p_{d z i w e j}=\frac{1}{n} \sum_{i=1}^{n} p_{d z i w y j}
$$

where:

$p_{\text {dziwej }}$ - the average value of pressure in front of the flow divider, $p_{d z i w y j}$ - the pressure behind the flow divider.

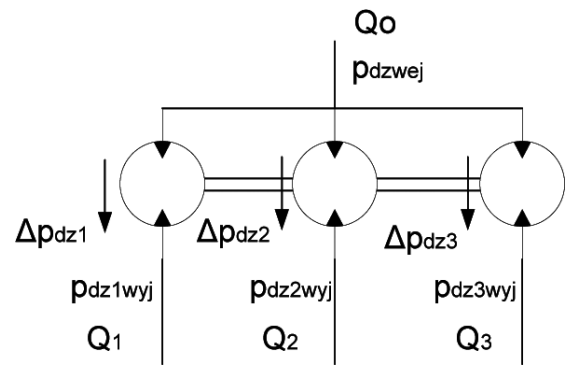

Fig. 9. Flow and pressure division in the gear flow divider

From the aforementioned relation, one can conclude that particular sections of the divider may operate in the system as a motor reducing the pressure or as a pump causing pressure increase in the line behind the divider. In the two states, the leaks occur, which are dependent on the values of pressure drops, causing the kinematic discrepancy compensation.

For the tests, it was assumed that the maximum value of kinematic discrepancy compensation of the system occurs when the pressure drop on one of the motors drops to zero (the wheel rotates freely but does not produce any driving force), and the pressure drop on the other motor reaches the maximum value. 
First, the case of driving straight was considered (Fig. 10), in which the flow divider is at the runoff line of the hydraulic motors. As a result, pressure in the lines behind the flow divider and the suction pump, in accordance with relation (6) would be $p_{4}=20 \mathrm{MPa}$, while the growth in pressure generated by the hydraulic pump would be $\Delta p_{p}=10 \mathrm{MPa}$.

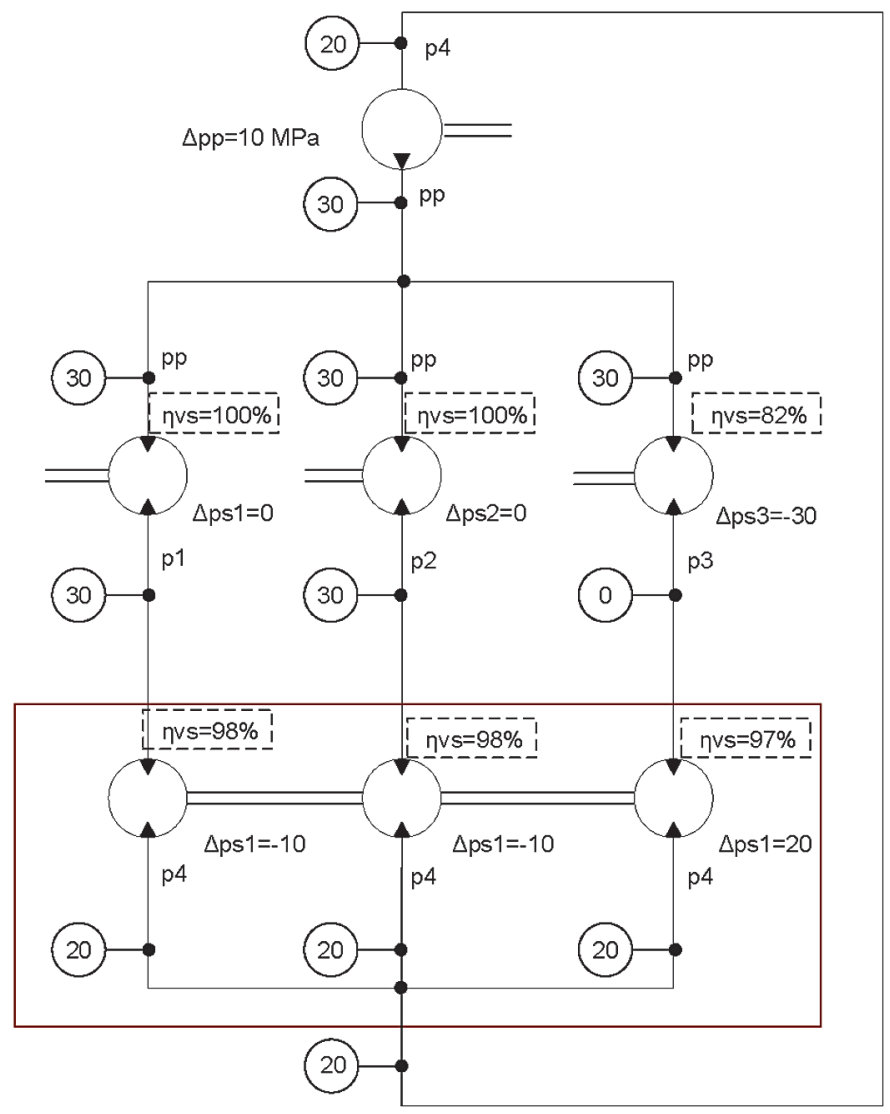

Fig. 10. Connecting in series for driving straight ahead - the numerical values of the pressures are indicated in $\mathrm{MPa}$

The theoretical values of the capacity for compensating the kinematic discrepancy determined according to this algorithm are indicated for a set consisting of:

1. gear motors and a gear flow divider with the 5\% accuracy - Table 1 ;

2. gear motors and a gear flow divider with the $2 \%$ accuracy - Table 2 ;

3. piston motors and a throttling divider whose accuracy of division of the working medium is between $9 \% \div 30 \%$ for the work with the efficiency $Q_{p}=36 \mathrm{dm}^{3} / \mathrm{min}-$ Table 3 . 
Table 1

Comparison between the results of analysis of a system consisting of gear motors and a gear flow divider with the 5\% accuracy

\begin{tabular}{|c|c|c|c|}
\hline element & & $\Delta p, \mathrm{MPa}$ & $\eta_{v}$ \\
\hline \multicolumn{2}{|l|}{ hydraulic motor } & 30 & $82.0 \%$ \\
\hline \multirow{3}{*}{ gear flow divider } & 1 & -10 & $98.3 \%$ \\
\hline & 2 & -10 & $98.3 \%$ \\
\hline & 3 & 20 & $96.7 \%$ \\
\hline \multicolumn{2}{|l|}{ sum of leakages } & $\Sigma$ & $77.9 \%$ \\
\hline compensation of the discrepancy & & & $22.1 \%$ \\
\hline
\end{tabular}

Table 2

Comparison between the results of analysis of a system consisting of a piston engine and a gear flow divider with the $2 \%$ accuracy

\begin{tabular}{|c|c|c|c|}
\hline \multicolumn{2}{|l|}{ element } & $\Delta p, \mathrm{MPa}$ & $\eta_{v}$ \\
\hline \multicolumn{2}{|l|}{ hydraulic motor } & 30 & $86.0 \%$ \\
\hline \multirow{3}{*}{ gear flow divider } & 1 & -10 & $99.3 \%$ \\
\hline & 2 & -10 & $99.3 \%$ \\
\hline & 3 & 20 & $98.7 \%$ \\
\hline \multicolumn{2}{|l|}{ sum of leakages } & $\Sigma$ & $84.3 \%$ \\
\hline \multicolumn{2}{|c|}{ compensation of the discrepancy } & & $15.7 \%$ \\
\hline
\end{tabular}

Table 3 .

Comparison between the results of analysis of a system consisting of a piston engine and a throttling divider $\left(9 \% \div 30 \%\right.$ with the efficiency $\left.Q_{p}=36 \mathrm{dm}^{3} / \mathrm{min}\right)$

\begin{tabular}{|c|c|c|c|c|}
\hline \multicolumn{2}{|l|}{ element } & $\Delta p, \mathrm{MPa}$ & & $\eta_{v}$ \\
\hline \multicolumn{2}{|l|}{ hydraulic motor } & 30 & $86.0 \%$ & $\div 86.0 \%$ \\
\hline \multirow{3}{*}{ gear flow divider } & 1 & -10 & $97.0 \%$ & $\div 90.0 \%$ \\
\hline & 2 & -10 & $97.0 \%$ & $\div 90.0 \%$ \\
\hline & 3 & 20 & $97.0 \%$ & $\div 90.0 \%$ \\
\hline \multicolumn{2}{|l|}{ sum of leakages } & $\Sigma$ & $80.9 \%$ & $\div 69.7 \%$ \\
\hline \multicolumn{2}{|l|}{ compensation of the discrepancy } & & $19.1 \%$ & $\div 30.3 \%$ \\
\hline
\end{tabular}

Considering the case in which a vehicle moves backwards in the off-road mode (Fig. 11) for the assumed values of pressure drops $\Delta p_{s 1}=0 \mathrm{MPa}$, $\Delta p_{s 2}=0 \mathrm{MPa}, \Delta p_{s 3}=30 \mathrm{MPa}$, and assuming that the pressure at runoff lines from the motors has the value of $p_{4}=0 \mathrm{MPa}$, one obtains the pressure on the high pressure line of hydraulic motors $p_{1}=0 \mathrm{MPa}, p_{2}=0 \mathrm{MPa}, p_{3}=30 \mathrm{MPa}$. As a result, the pressure on the inlet line to the flow divider in accordance with relation (5) would be $p_{p}=10 \mathrm{MPa}$. 


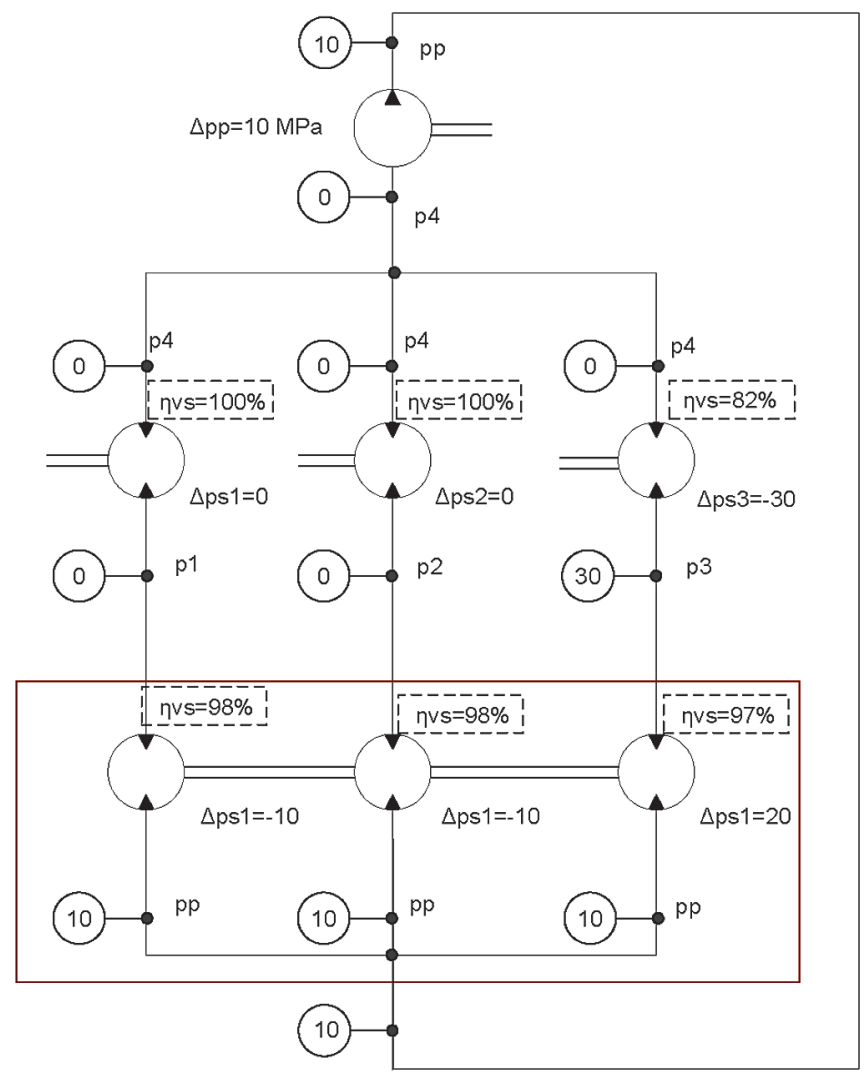

Fig. 11. Connecting the motors in parallel for driving straight ahead - numerical values of the pressures are indicated in $\mathrm{MPa}$

It can be concluded from the analysis that assuming by analogy the same hydraulic subassemblies and values of pressure drops on elements, the same amount of the kinematic discrepancy compensation would be obtained.

In spite of the fact that the pressure drop on the hydraulic motor is $\Delta p_{s 3}=30 \mathrm{MPa}$, small values of pressure drops on other motors cause considerable reduction of pressure generated by the pump $p_{p}=10 \mathrm{MPa}$. It is the result of the operation of two sections of the divider, which took over the function of the pump, and one section performing the function of the motor. Thus, in such a case, there is the need for protecting the line behind the flow divider against an excessive increase in the pressure.

During the tests of the kinematic discrepancy compensation capacity in the parallel system, the analysis was conducted for a greater range of driving speed $v_{j}=(2 \mathrm{~m} / \mathrm{s}, 3 \mathrm{~m} / \mathrm{s}, 4 \mathrm{~m} / \mathrm{s}, 5 \mathrm{~m} / \mathrm{s}, 6 \mathrm{~m} / \mathrm{s}, 7 \mathrm{~m} / \mathrm{s})$, and for the values of pressure drops at the hydraulic motors $\Delta p_{s}=(30 \mathrm{MPa}, 20 \mathrm{MPa}, 10 \mathrm{MPa})$. The results are presented in Figs 12-14. 


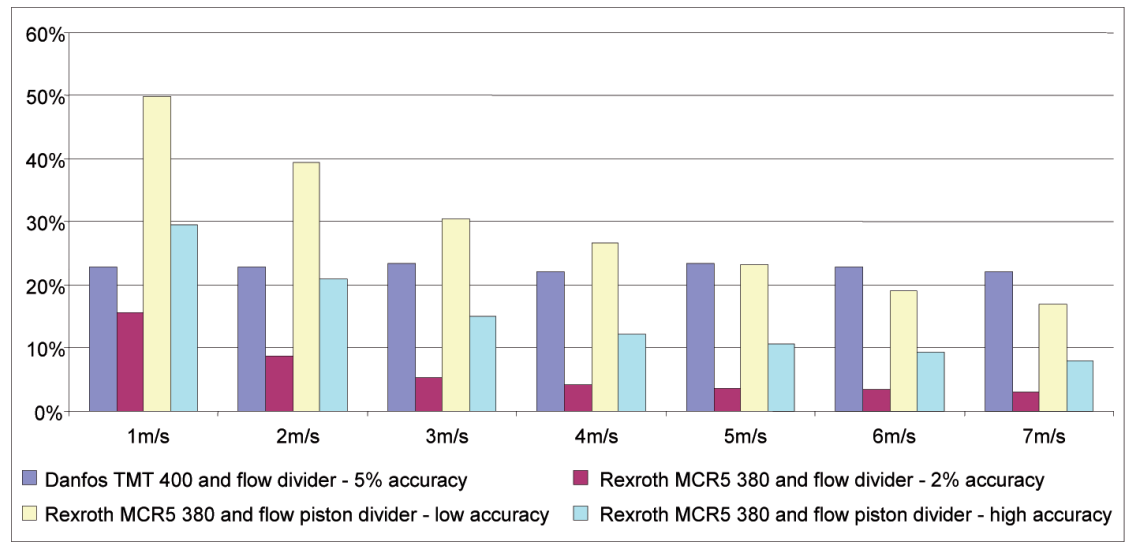

Fig. 12. Capacity for compensating the kinematic discrepancy of the system for different driving speeds in the all-terrain mode in the case of a drop in pressure in the hydraulic motor $\Delta p_{s}=30 \mathrm{MPa}$

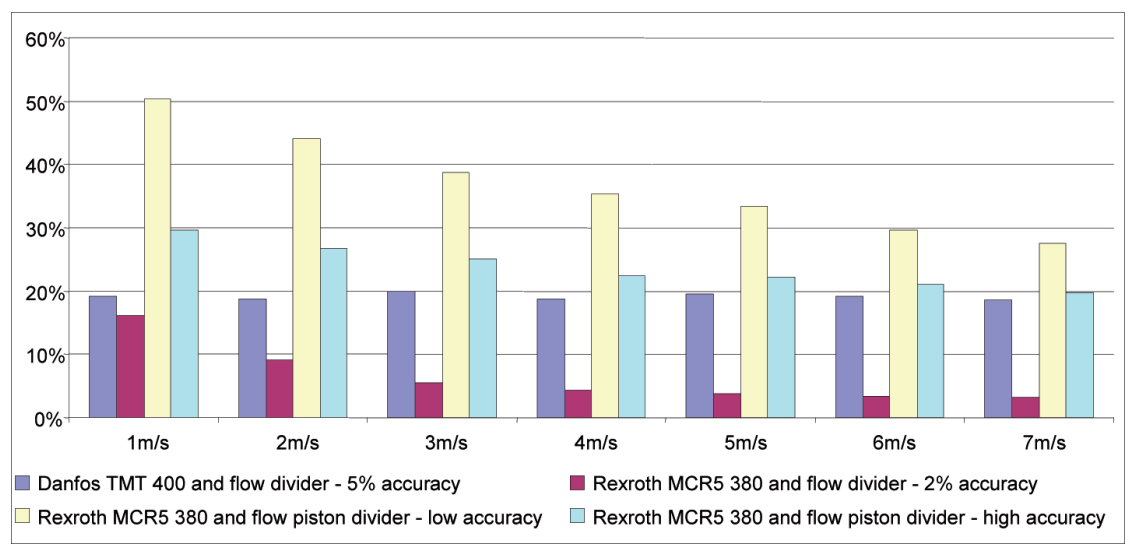

Fig. 13. Capacity for compensating the kinematic discrepancy of the system for different driving speeds in the all-terrain mode in the case of a drop in pressure in the hydraulic motor $\Delta p_{s}=20 \mathrm{MPa}$

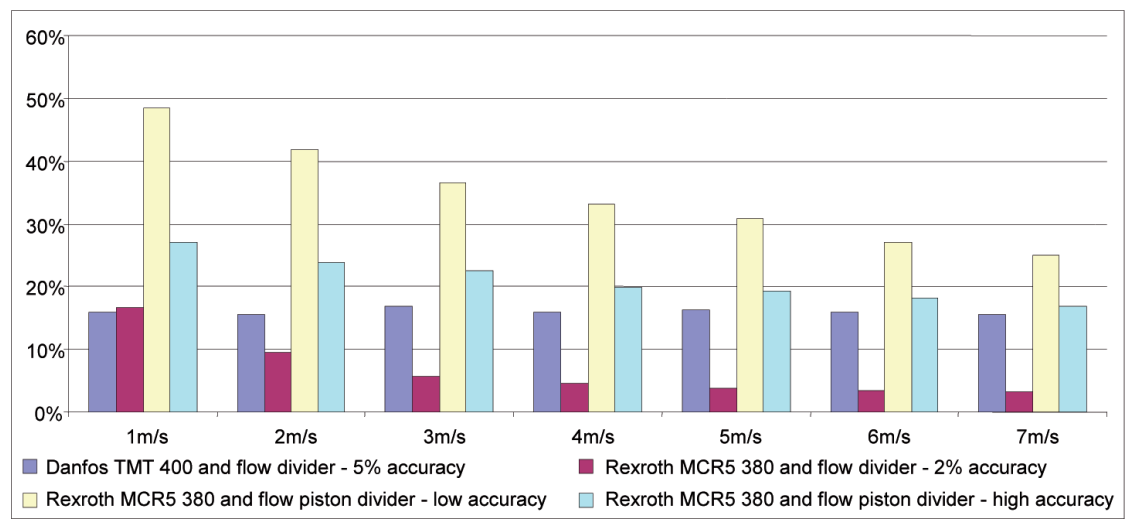

Fig. 14. Capacity for compensating the kinematic discrepancy of the system for different driving speeds in the all-terrain mode in the case of a drop in pressure in the hydraulic motor $\Delta p_{s}=10 \mathrm{MPa}$ 


\subsection{Testing the capacity of kinematic discrepancy compensation in the road driving mode}

For driving in the race mode, in which the motors are powered as a series, one assumes the speed of the vehicle $v_{j}=10 \mathrm{~m} / \mathrm{s}$. The values of pressure of hydraulic motors were assumed in the same way as for the parallel connection. The values for the analysis are presented in Fig. 15.

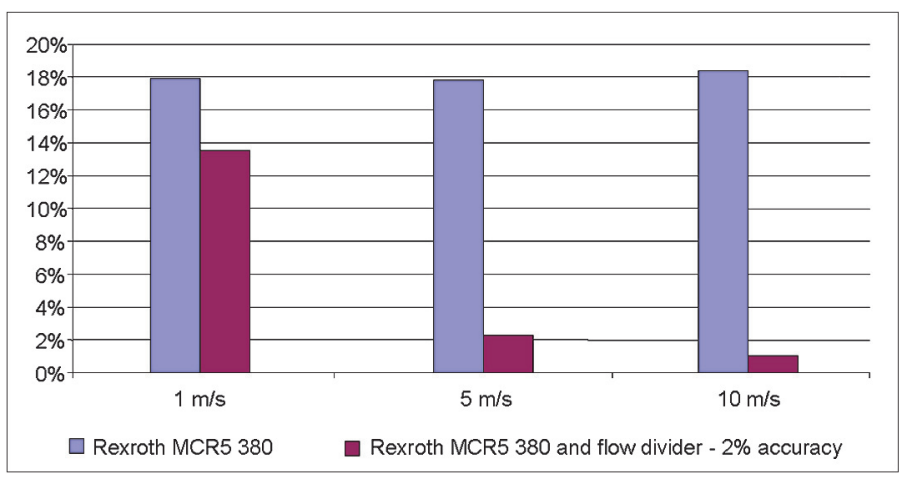

Fig. 15. Capacity for compensating the kinematic discrepancy of the system for different driving speeds in the road mode in the case of a drop in pressure in the hydraulic motor $\Delta p_{s}=30 \mathrm{MPa}$

From the analysis of the series system it can be concluded that the maximum capacity for the kinematic discrepancy compensation of the serial system results from the total value of leaks of one of the motors and amounts to $18 \%$ for toothed motors and $14 \%$ for piston motors. However, it is too large a simplification, as the volumetric losses drained from each of the motors to the tank were not considered here. Because of the leaks, even when driving straight in a flat area with identical values of pressure decrease, there is a kinematic discrepancy resulting from the decrease in the dose of the working agent for each of the motors.

\section{Conclusions}

The analyses conducted have shown that shaping the characteristics of the kinematic discrepancy compensation in the hydrostatic drive system should be achieved in the following ways: by selecting appropriate structure for the system and by choosing subassemblies of the hydraulic system, which should be examined from the perspective of the operation of the whole system.

Ensuring high efficiency of the system operation requires the application of hydraulic motors characterized by high volumetric efficiency, and flow di- 
viders with the desired characteristics of dividing the factor flow. Taking the above into consideration, we have obtained the most beneficial characteristics by applying piston motors and a throttle flow divider. In such a way, it was possible to achieve the maximum capacity of the kinematic discrepancy compensation for driving at small speeds in the range of ca. $30 \div 50 \%$, while at higher speeds - in the range of $8 \div 17 \%$.

Manuscript received by Editorial Board, May 14, 2013

final version, April 09, 2015

\section{REFERENCES}

[1] Sprawka P.: The methods of evaluation the mobility of off-road vehicles. Solid State Phenomena Vol. 180, Trans Tech Publications, Switzerland, 2011. pp. 355-365.

[2] Budny E.: Napęd i sterowanie układów hydraulicznych w maszynach roboczych. ITE, Radom, 2001.

[3] Bartnicki A., Sprawka P.: Zastosowanie hydrostatycznych układów napędowych we współczesnych maszynach i pojazdach lądowych. LOGITRANS, Szczyrk, 2008.

[4] Studziński K.: Teoria i sterowanie. Samochód. WKŁ, Warszawa, 1980.

[5] Comellas M., Pijuan J., Potau X., Nogue's M., Roca J.: Active bogies, chassis levelling and transmission efficiency for a vehicle operating in rough terrain. Journal of KONES Powertrain and Transport, $\mathrm{nr} 42007$.

[6] Comellas M., Pijuan J., Potau X., Nogue's M., Roca J.: Analysis of a hydrostatic transmission driveline for its use in off-road multiple axle vehicles. Journal of Terramechanics, nr 49. 2012.

[7] Stryczek S.: Napęd hydrostatyczny. Tom I. Wydawnictwa Naukowo-Techniczne, Warszawa, 2005.

[8] Bartnicki. A., Muszyński. T.: Koncepcja układu napędowego dla bezzałogowej platformy lądowej o skręcie burtowym. Międzynarodowa Konferencja Naukowo-Techniczna Napędy i Sterowania Hydrauliczne i Pneumatyczne, Wrocław, 2010. pp. 70-75.

[9] Łopatka, M. J.: Praca zbiorowa, Inżynieryjny Robot Wsparcia IOD/EOD - usuwania ładunków niebezpiecznych, Sprawozdanie z projektu rozwojowego Nr OR00001205/PBR, Warszawa, 2011.

[10] Rexroth Bosch Group: Traction module (flow divider) RE 64592/06.06, Technical data, 2006.

[11] Rexroth Bosch Group: Radial Piston Motor (Multi-Stroke) MCR5, RE 15206/07.09, Technical data, 2006.

[12] Danfoss, Orbital Motors OMS, OMT and OMV Orbital Motors, Technical Information, 2014.

\section{Niezgodność kinematyczna hydrostatycznych układów napędowych Bezzalogowych Platform Lądowych}

\section{Streszczenie}

W opracowaniu przedstawiony został problem niezgodności kinematycznej hydrostatycznych układów napędowych pojazdów wysokiej mobilności oraz jej wpływ na występowanie niekorzystnego zjawiska mocy krążącej. Ponadto zaprezentowane zostały rozważania teoretyczne dotyczące zdolności kompensacji niezgodności kinematycznej przez hydrostatyczny układ napędowy na podstawie badań z wykorzystaniem charakterystyk statycznych. 